\section{BMJ}

Open

Gastroenterology

\title{
An 18-year-old girl with retrosternal burning discomfort: a bitter pill to swallow
}

\author{
Mahmoud Gouda, ${ }^{1}$ Ayman Elkholi, ${ }^{1}$ Thomas H Tranah (D) , ${ }^{1,2}$ \\ Debbie L Shawcross ${ }^{1,2}$
}

To cite: Gouda M, Elkholi A, Tranah TH, et al. An 18-year-old girl with retrosternal burning discomfort: a bitter pill to swallow. BMJ Open Gastro 2021;8:e000767. doi:10.1136/ bmjgast-2021-000767

Received 10 August 2021 Accepted 10 December 2021
Check for updates

\section{(c) Author(s) (or their} employer(s)) 2021. Re-use permitted under CC BY-NC. No commercial re-use. See rights and permissions. Published by BMJ.

${ }^{1}$ Institute of Liver Studies, King's College Hospital NHS Foundation Trust, London, UK ${ }^{2}$ Department of Inflammation Biology, School of Immunological Sciences, Faculty of Life Sciences and Medicine, King's College London, London, UK

\section{ABSTRACT}

Caustic injury secondary to impaction of ingested batteries is a potentially severe cause of oesophageal injury with an increasing incidence that reflects consumer trends and the utilisation of compact electronic devices. Delays to recognition and management are associated with increased risk of complications, morbidity and mortality. In this manuscript, we describe a case presentation and literature review of a patient presenting with upper oesophageal odynophagia after the deliberate ingestion of multiple foreign bodies.

\section{CASE HISTORY}

An 18-year-old woman presented with retrosternal burning and discomfort 2 hours after the deliberate ingestion of multiple foreign bodies, at the same time she had percutaneously penetrated her abdomen with shards of broken mirror in addition to sustaining lacerations to her wrists and lower limbs. The patient had a history of autism, obsessive-compulsive disorder and borderline personality disorder with multiple previous suicide attempts and an extensive history of deliberate self-harm. Her admission vital signs were normal, abdominal examination revealed multiple scars from previous selfharm with three new puncture wounds to the abdomen, there was no evidence of peritonism.

\section{INVESTIGATIONS}

Initial laboratory tests showed haemoglobin 121 (115-155g/L), white cell count $8.34\left(4.0-11.0 \times 10^{9} / \mathrm{L}\right)$, C reactive protein $<1.0 \mathrm{mg} / \mathrm{L}$ and lactate $1.0 \mathrm{mmol} / \mathrm{L}$. Radioopaque foreign bodies were identified in the oesophagus, stomach, colon and peritoneal space on CT imaging (figure 1A).

\section{MANAGEMENT}

The patient proceeded to emergency endoscopy which took place 5 hours after ingestion of the foreign bodies (figure 1B,C). Endoscopy demonstrated a caustic oesophageal injury with circumferential ulceration and scattered necrosis at the level of the aortic arch where one of the batteries had impacted. Three of the four batteries were retrieved endoscopically (figure 2 ) and the oesophagus was irrigated and inspected. A laparoscopy and washout was performed removing penetrating foreign bodies from her abdomen (glass shards and x1 needle, figure 2); bowel preparation was administered postoperatively to aid transit of one battery that had progressed beyond the limit of endoscopic retrieval. The patient was placed nil by mouth on broad spectrum antimicrobial prophylaxis in addition to gastric acid suppression.

\section{OUTCOME}

Postprocedurally the patient reported persistent burning retrosternal discomfort that gradually improved without further complication.

\section{DISCUSSION}

Most ingested foreign bodies pass spontaneously through the gastrointestinal (GI) tract, however, $10 \%-20 \%$ require endoscopic extraction and $1 \%$ require surgical extraction or intervention for treatment of complications. ${ }^{1}$ The majority of button battery ingestions occur in paediatric populations and in vulnerable adult groups with lack of risk perception or accidental ingestion representing the most common circumstances of ingestion. ${ }^{2}$ The oesophagus is the most common site of foreign body impaction typically occurring at one of four classical points of narrowing, the upper oesophageal sphincter, the aortic arch, adjacent to the left 

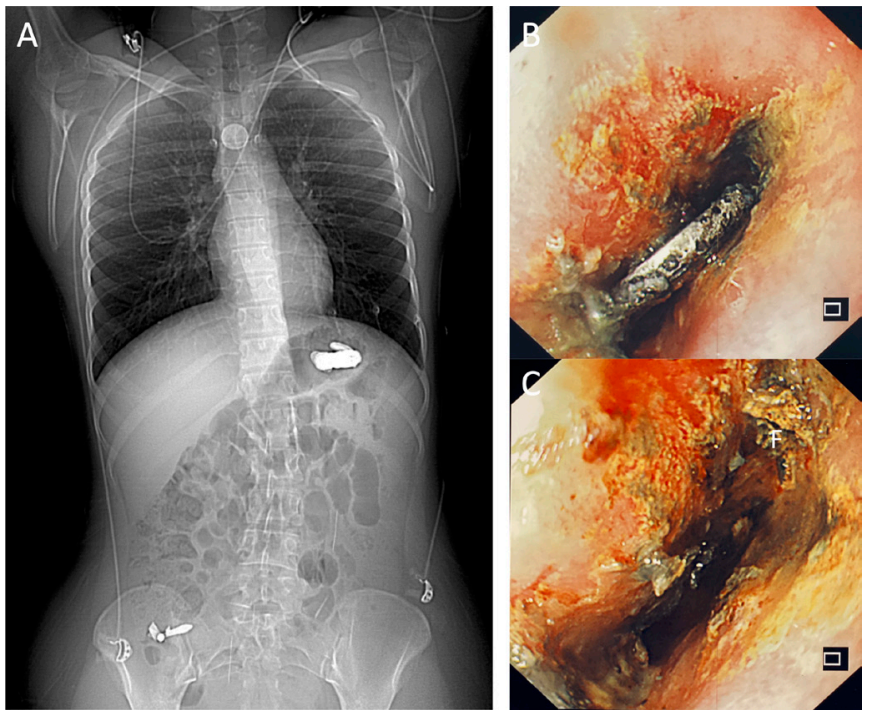

Figure 1 (A) Axial CT imaging demonstrating radio-opaque foreign bodies in the oesophagus, stomach and caecum $(B, C)$ endoscopic images of impacted button battery at $22 \mathrm{~cm}$ with surrounding mucosal injury, there was oedema, inflammation and circumferential ulceration with scattered necrosis consistent with caustic oesophageal injury.

main bronchus and the oesophageal hiatus through the diaphragm. ${ }^{3}$

The clinical presentation of impacted oesophageal batteries is variable and depends on the impaction site and time since ingestion. Early symptoms include retrosternal discomfort, heartburn, vomiting, dysphagia and odynophagia. While patients presenting at a later stage can present with sequelae of severe injury with haematemesis, melena and severe abdominal pain.
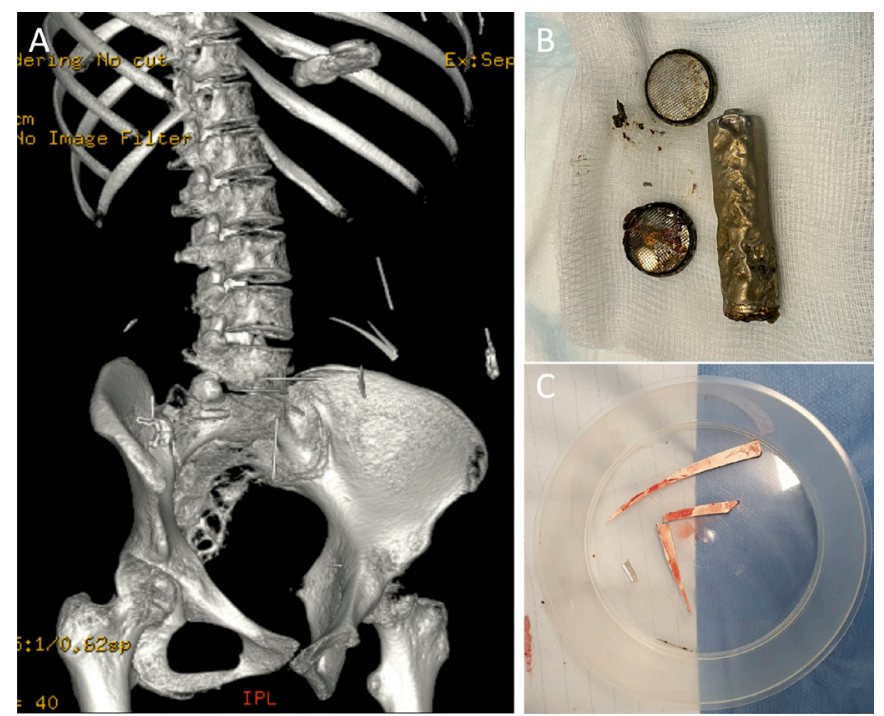

Figure 2 (A) Volume-rendered CT image reconstruction demonstrating sharp linear fragments penetrating through the abdominal wall in addition to an AA and lithium battery in the gastric fundus $(B)$ retrieved button batteries and AA battery at endoscopy $(\mathrm{C})$ retrieved mirror shards and hypodermic needle at laparoscopy.
Batteries can cause tissue damage through three main mechanisms, oesophageal impaction causes the generation of an electrical current and thermal injuries with coagulative necrosis, in addition to pressure necrosis and chemical injury; a process which occurs within as little as 15 min. ${ }^{45}$ This is seen more often when batteries get impacted in the oesophagus where, due to its narrow nature, continuous contact of both poles of the batteries with the oesophageal mucosa occurs accelerating the tissue injury. However, oesophageal mucosal damage can also be found in cases where the batteries have passed distally to the stomach or GI tract. Early endoscopic evaluation of caustic injuries to the upper GI tract is safe and important to grade the degree of mucosal injury through the Zargar classification system, direct appropriate management and prognosticate risk of early and late complications. ${ }^{6}$

Patients presenting with a history of foreign body ingestion should have X-rays of the neck, chest and abdomen performed to identify the location, shape and number of objects. Due to the rapid time to injury, European guidelines recommend emergency endoscopy for batteries lodged within the oesophagus, ideally within 2 hours of ingestion, but at the latest within 6 hours. ${ }^{7}$ Delay to retrieval of impacted oesophageal batteries can lead to severe mucosal damage such as oesophageal perforation, mediastinitis and aorto-oesophageal fistulation in addition to late complications of oesophageal structuring. The risk of mucosal injury from batteries that have passed through the oesophagus is low compared with that associated with oesophageal impaction, however, there remains potential for injury secondary to leakage of corrosive agents and removal of batteries from the stomach within 24 hours of ingestion is recommended. Once batteries have passed beyond the duodenum, guidelines recommend conservative management and follow-up by plain radiography every 3-4days as the risk of complications decreases significantly.

Contributors $M G$ and $A E$ wrote this manuscript and performed the literature review. The manuscript was reviewed and edited by TT and DLS.

Funding The authors have not declared a specific grant for this research from any funding agency in the public, commercial or not-for-profit sectors.

Competing interests None declared.

Patient consent for publication Consent obtained directly from patient(s).

Provenance and peer review Not commissioned; internally peer reviewed.

Data availability statement Data sharing not applicable as no datasets generated and/or analysed for this study. Not applicable.

Open access This is an open access article distributed in accordance with the Creative Commons Attribution Non Commercial (CC BY-NC 4.0) license, which permits others to distribute, remix, adapt, build upon this work noncommercially, and license their derivative works on different terms, provided the original work is properly cited, appropriate credit is given, any changes made indicated, and the use is non-commercial. See: http://creativecommons.org/ licenses/by-nc/4.0/.

ORCID iD

Thomas H Tranah http://orcid.org/0000-0001-9290-3044 


\section{REFERENCES}

1 Becq A, Camus M, Dray X. Foreign body ingestion: dos and don'ts. Frontline Gastroenterol 2021;12:664-70.

2 Labadie M, O'Mahony E, Capaldo L, et al. Severity of button batteries ingestions: data from French poison control centres between 1999 and 2015. Eur J Emerg Med 2018;25:e1-8.

3 Wang X, Su S, Chen Y, et al. The removal of foreign body ingestion in the upper gastrointestinal tract: a retrospective study of 1,182 adult cases. Ann Transl Med 2021;9:502.

4 Tanaka J, Yamashita M, Yamashita M, et al. Esophageal electrochemical burns due to button type lithium batteries in dogs. Vet Hum Toxicol 1998;40:193-6.
5 Choi K, Mogami T, Suzuki T. Experimental study on detection of electrostatic discharges generated by polymer granules inside a meta silo. Rev Sci Instrum 2014;85:045001.

6 Zargar SA, Kochhar R, Mehta S, et al. The role of fiberoptic endoscopy in the management of corrosive ingestion and modified endoscopic classification of burns. Gastrointest Endosc 1991;37:165-9.

7 Birk M, Bauerfeind P, Deprez PH, et al. Removal of foreign bodies in the upper gastrointestinal tract in adults: European Society of gastrointestinal endoscopy (ESGE) clinical guideline. Endoscopy 2016;48:489-96. 